\title{
O FUTURO DA CRIAÇÃO: TENTATIVAS PARA O DIÁLOGO ENTRE TEOLOGIA E CIÊNCIA A PARTIR DA CRISE ECOLÓGICA
}

\author{
THE FUTURE OF CREATION: ATTEMPTS AT DIALOGUE BETWEEN THEOLOGY \\ AND SCIENCE FROM THE ECOLOGICAL CRISIS
}

\author{
José Armando Vicente ${ }^{1}$
}

RESUMO: Pergunta-se: o que significa, pois, estudar o "futuro da criação"? De fato, diante da atual crise ecológica, urge perguntar se a criação tem futuro. Sem dúvida, não é uma empresa fácil responder a essa questão. A ideia o "futuro da criação" pode ser classificada de várias maneiras, conforme se refira à meta (telos) ou fim (finis) da criação. Se a criação possui uma meta, esta consiste em que ela se cumpra, e a criação caminha passo a passo e com segurança rumo a esta meta. As leituras científicas de Friedman, Lamaitre, Hubble, Hyle, Hsu nos ajudarão a resolver o problema no contexto do futuro da criação: a idéia comum é que existe, não obstante, uma marcante assimetria entre o estado inicial e o estado final da criação. De outro lado, a leitura cristã de Okure, Moltmann, Penha, Boff, nos mostrará que todas as coisas foram criadas com vistas ao Messias, pois o Messias redimirá todas as coisas para sua verdade e as reunirá para o reino de Deus e, dessa forma, levará a criação à consumação.

Palavra-chave: Criação. Futuro. Diálogo.

SUMMARY: The question is: what does it mean, then, to study the "future of creation"? In fact, given the current ecological crisis, it is urgent to ask whether creation has a future. Undoubtedly, it is not an easy company to answer this question. The idea of the "future of creation" can be classified in various ways, depending on whether it refers to the goal (telos) or end (finis) of creation. If creation has a goal, this consists in its being fulfilled, and creation walks step by step and safely towards that goal. The scientific readings of Friedman, Lamaitre, Hubble, Hyle, Hsu will help us to solve the problem in the context of the future of creation: the common idea is that there is nevertheless a marked asymmetry between the initial state and the final state of creation. On the other hand, the Christian reading of Okure, Moltmann, Pena, Boff, will show us that all things were created with a view to the Messiah, for the Messiah will redeem all things to its

\footnotetext{
'Doutor em Teologia Sistemática (2016) pela Faculdade Jesuíta de Filosofia e Teologia - Belo Horizonte - Brasil. Doutorando em Educação pela Universidade Internacional Iberoamericana - UNINI-MX. Linha de Pesquisa: Multiculturalidade, Interculturalidade em educação. Pesquisador nas seguintes áreas: Teologia das religiões; Pluralismo religioso. Diálogo Inter-religioso; Teologia Africana; as religiões; Educação: Multiculturalismo e Interculturalidade; Bilíngüismo e Plurilínguismo, Multilinguismo. Mestre em Teologia Sistemática (2012) pela Faculdade Jesuíta de Filosofia e Teologia - Belo Horizonte - Brasil. . Pós-graduando em Educação Bilíngui e Plurilíngui na PUC - MG (Pontifícia Universidade Católica de Minas Gerais. Pós-graduando em Educação Bilíngui e Plurilíngui na PUC - MG (Pontifícia Universidade Católica de Minas Gerais. Pós-graduação Lato Sensu em Especialização para Formadores de Presbíteros (2010), no Instituto Santo Tomás de Aquino - Belo Horizonte - Brasil; Pós-graduação Lato Sensu em Especialização em Sociologia e Psicologia Social (2019), na Universidade Estácio de Sá. Graduado em Filosofia (1999), no Seminário Maior de Filosofia em Moçambique; graduado em Teologia (2005) no Instituto Santo Tomás de Aquino Belo Horizonte - Brasil. E-mail: josarvicente@yahoo.com.br.
} 
truth and gather them together for the kingdom of God and hence form, will lead creation to consummation.

Keyword: Creation. Future. Dialogue.

\section{INTRODUÇÃO}

O presente artigo procurará refletir sobre o futuro da Criação, no contexto da atual crise ecológica. Para isso, será apresentada a atual crise ecológica. Diante dessa crise, serão apresentadas reflexões ou as contribuições científicas de alguns cosmólogos sobre o futuro da criação; também será imperioso uma reflexão a partir da fé cristã para que se possa manter um tentativa do diálogo entre a ciência e a fé/teologia cristã

Nossa motivação neste artigo é mostrar à comunidade científica e aos grupos religiosos pessimistas e fundamentalistas que, apesar da atual crise ecológica, não estamos no fim do mundo, pois tudo se ordena a Deus; ele é o fim último de tudo; o fim de tudo (ICor $15,24-28)$ - no duplo sentido de término e finalidade - télos - é a soberania de Cristo, em Deus.

O método empregado é a revisão de literatura sobre a criação o futuro da Criação conforme realizada pelos seguintes autores: Moltmann, Okure, Boff, Pena. Estes autores são, na atualidade, referência sobre os temas da ecologia e a criação.

\section{A CRISE ECOLÓGICA}

Vivemos numa atual situação de crise ecológica. Os grandes problemas ecológicos se resumem nos seguintes aspectos: contaminação ambiental, a exploração dos recursos naturais, o efeito estufa, o buraco do ozono. Como conseqüência desses problemas, assiste-se, em nível mundial, as transformações climáticas (grandes secas e enchentes), problemas agrícolas.

No Brasil, concretamente, podemos citar inicialmente: a )as grandes queimadas que estão acontecendo na Amazônia - 2019; b) a grande seca que aconteceu na Amazônia2005: igarapés secos, barcos encalhados em bancos de areia dos rios, mortalidade de peixes, população isolada sem ter como se locomover e sem ter o que comer; c) a grande enchente que atingiu o Nordeste Brasileiro - 2009: os desastres provocados pelas fortes chuvas e enchentes deixaram 294.46I pessoas desalojadas; 135.592 desabrigados; d) os temporais que 

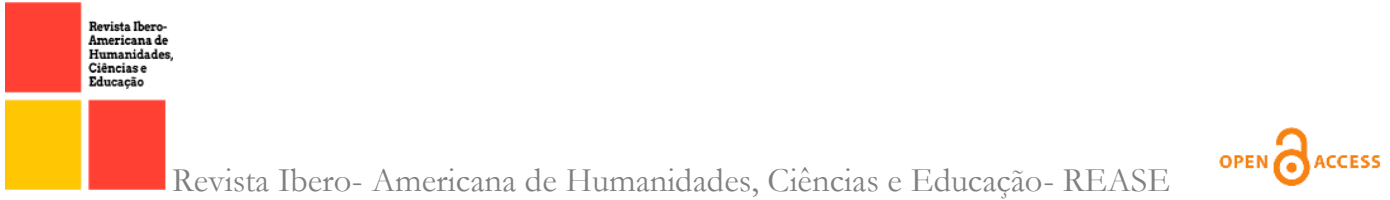

atingiram o Sul e Sudeste do país em o8 de Setembro de 2009: 07 mortos, 138 feridos; 5.836 desalojados.

Todos esses indicadores ecológicos coincidem ao assinalar que estamos vivendo uma situação da saturação, de poluição de água, do solo, do ar e a degradação da terra, a perda da biodiversidade.

Esses problemas influenciam profundamente a qualidade da vida. No dizer de Fritjof Capra, esses problemas não podem ser entendidos isoladamente. São problemas sistêmicos, ou seja, estão interligados e são interdependentes.

\footnotetext{
A escassez dos recursos e a degradação do meio ambiente combinam-se com a população em rápida expansão, o que leva ao colapso das comunidades locais e à violência étnica e tribal que se tornou a característica mais importante da era pósguerra fria (CAPRA, 1996, p. 23).
}

Os problemas ecológicos, portanto, têm despertado preocupação em todas as esferas da população mundial e brasileira.

Em suma, olhando, hoje, o nosso planeta, vemos as alterações climáticas e a poluição crescente e ameaçadora. Sentimos medo diante da escassez de água, que não só nos mata a sede, mas agrava a questão da escassez de alimentos. Assistimos perplexos, a extinção de espécies inteiras e modificações genéticas acontecendo.

Esses fatos devem provocar alguns questionamentos para nós. Inicialmente deve-se perguntar se esses fatos são conseqüências da própria natureza ou se são resultados da ação humana. Quem é responsável por este estado de coisas? qual é o futuro da criação?

\section{CAUSAS DA ATUAL CRISE ECOLÓGICA}

Diversos autores radicais do movimento ecológico - dentre os quais, Boff e Leone - tentam articular a atual crise global do meio ambiente com a questão da espiritualidade e das tradições religiosas. Eles apontam, em linhas gerais, uma ampla discussão sobre a doutrina judaico-cristã como a origem da atual crise ecológica. Afinal, pergunta-se: a religião monoteísta, inaugurada com o judaísmo e expandida com o cristianismo, tornou-se um fator de contribuição para a atual crise ecológica?

De acordo com White (1967), a teologia judaico-cristã configurou um sistema de pensamento a partir do qual foi possível, na Modernidade, a associação entre ciência e tecnologia. Este casamento gerou o projeto da tecno-ciência da Pós-modernidade, que aparece como resultante do sistema de pensamento teológico, no qual se afirma a 
existência da natureza com a única finalidade de servir ao ser humano, podendo ser explorada e dominada conforme os interesses exclusivamente humanos.

Uma revisão da literatura sobre o sentido antiecológico da tradição judaicocristã, conforme realizada por Boff (1993), pode ser apresentada a partir de seis perspectivas: o patriarcalismo; o monoteísmo; o antropocentrismo; a ideologia tribalista da eleição; a crença na queda da natureza. Cabe retomar, em linhas gerais, essa discussão para entendermos qual o sentido do sagrado na Pós-modernidade.

O patriarcalismo é o quadro cultural da Antiguidade Clássica que marca a produção dos textos do Antigo e Novo Testamento. Em seu ponto de encontro com o monoteísmo, produz a imagem masculina de um único deus masculino. Segundo Gray (198I), a dimensão feminina tornar-se secundária e deslegitimada, acarretando um desequilíbrio de poder na relação entre os gêneros, uma ruptura de uma ecologia social do masculino e feminino.

O eixo do embate do monoteísmo judaico-cristão se deu contra o politeísmo em seus diversos matizes. Segundo Hervieu-Léger (1993), é exatamente por causa dessa polêmica com o paganismo e seu politeísmo que o cristianismo aboliu a presença das energias divinas no cosmos e, principalmente, no ser humano. As religiões pagãs entendem o cosmos, em sua multiplicidade de manifestações, como portador de sacralidade e mistério. No paganismo, o homem é o lugar da habitação de múltiplos centros de energias cósmicas, vinculados com uma forma primordial de energia universal presente no cosmos.

O antropocentrismo moderno tem feito das citações bíblicas para justificar a noção de progresso ilimitado como base da civilização industrial e o domínio destruidor do homem sobre a natureza. Mas não é possível evitar o sentido destes textos. Até mesmo uma nova tradução no contexto cultural da Antiguidade do Oriente Médio vem sendo tentada para tentar minimizar o teor antiecológico do monoteísmo judaico-cristão. Moltmann (1993), ao discutir a doutrina ecológica da criação, entende que "submetei a terra" possui o sentido de "tomai posse da terra", ordenando cada tribo a instalar-se em um território próprio.

A ideologia tribalista do "povo eleito de Deus". Esta arrogância da "eleição divina" produz, conseqüentemente, uma lógica da exclusão, instaurando a negação da diversidade e 
a submissão do diferente. A ideologia tribalista da eleição funcionou como um dispositivo de produção de subjetividade modelador da figura do "fiel dogmático", impondo ao Outro, no plano histórico, o seu desígnio divino. Portanto, um modo de subjetivação que rompe com a ética ecológica de solidariedade universal e aliança espiritual.

A quinta perspectiva a acarretar rupturas ecológicas surge da crença na queda da natureza: por causa do pecado original produzido pelo homem, o mundo perde o seu caráter sagrado e deixa de ser o lugar de habitação do Espírito para tornar-se a terra dos demônios. Diz Bradley (BRADLEY, 1993, p.87): “O mundo passa a ser visto como matéria decadente, pecaminosa e corrupta”. Esta noção do pecado humano como a causa dos "castigos" que sofre a Terra e tudo nela existente remete, mais uma vez, ao antropocentrismo, produzindo o "esquecimento" de que, antes mesmo de o homem aparecer na Terra, os terremotos, as dizimações das espécies e a morte já existiam. A "demonização da natureza" por causa da queda trouxe, entre outros resultados, uma falta de apreço pelo mundo material e por todo sentimento de plenitude e harmonia advindo da fruição da natureza. A centralidade do pecado e da queda da natureza é uma característica fundamental no cristianismo e está presente nas doutrinas de São Paulo, Santo Agostinho e Lutero.

Por sua vez, Leone defende também a tese segundo a qual o primeiro responsável da crise ecológica é a cultura judaico-cristã. Para o autor em questão, são essencialmente três as acusações dirigidas ao Cristianismo, a saber: a primeira é a atitude de domínio e de exploração indiscriminada da Terra, que vem do mandamento dado por Deus ao ser humano de "sujeitar" e "dominar toda a terra" (cf Gn 1,26-27); a segunda refere-se a dessacralização da Natureza operada por Cristianismo, rebaixando-a à categoria da realidade criada e, como tal, subtraída à esfera da intangibilidade que ela tinha nas religiões pagas; a terceira relaciona-se com o papel desempenhado pela religião judaicocristã no desenvolvimento da ciência e da tecnologia (LEONE, 200I, p. 35I).

Além dessas causas, a leitura histórica aponta quatro fatores principais: o primeiro nasce de uma dupla convicção equivocada (a inesgotabilidade dos recursos naturais e a capacidade de auto-reparação dos danos sofridos por parte da própria natureza); o segundo é relativo à lógica do lucro a alcançar com custos mínimos; o terceiro identifica-se com a política energética mundial que privilegiou fontes abundantes, embora 
poluentes (por exemplo, o petróleo e o carvão); o último é o reflexo do mundo atual de desenvolvimento ocidental que tende para o bem-estar e para o consumo sem qualquer preocupação com dados ambientais.

Os economistas, primordialmente preocupados com a geração de riquezas e bemestar, lançaram-se na tarefa de elaborar teorias que provocavam a otimização máxima do crescimento econômico, crescimento que se acelerou incrivelmente no decorrer dos últimos cinqüentas anos, tentando para metas cada vez mais altas e distantes. Em razão desse tipo de crescimento, o meio ambiente foi danificado (SANTA ANA, 1998, p. i8).

De fato, na origem da atual crise ambiental está o drástico desajuste entre os processos cíclicos, conservadores e autorrecorrentes da natureza, a ecosfera, e os processos lineares e inovadores que buscam a maximização a curto prazo dos benefícios privados humanos da tecnosfera.

Entre as causas socioculturais, destaca-se a assimetria na pegada ecológica dos diferentes lugares do mundo como um sinal de injustiça, já que o consumo de determinados países, como os Estados Unidos, por exemplo, excede abundantemente os limites da natureza. São diferentes modelos de vida que impactam de diferentes maneiras na atual crise ecológica e que também escancaram a desigualdade entre os povos.

Percebe-se, a partir do exposto, que a natureza deixa de ser o lugar da vida para tornar-se recurso a ser explorado e esgotado em vista a satisfação dos interesses econômicos.

Em suma, olhando, hoje, o nosso planeta, vemos as alterações climáticas e a poluição crescente e ameaçadora. Sentimos medo diante da escassez de água, que não só nos mata a sede, mas agrava a questão da escassez de alimentos. Assistimos perplexos, a extinção de espécies inteiras e modificações genéticas acontecendo. Mais uma vez, nos perguntamos: qual é o futuro da criação?

\section{AS LEITURAS CIENTÍFICAS SOBRE O FUTURO DA CRIAÇÃO}

\subsection{As bases científicas emergentes}

O futuro da criação é um tema, cientificamente falando, da cosmologia física. A exploração científica teórica da criação faz-se possível com a teoria da relatividade geral formulada por AlbertEinsten em 1915. Hoje, o eterno problema do futuro do universo é 
objeto de animadas controvérsias: astrofísicos e cosmólogos dividem suas preferências entre quatro opções possíveis.

- Universo em expansão limitada: segundo esta teoria, o universo tem um princípio e um final num decurso temporal finito

Afirma Pena:

\begin{abstract}
A "grande explosão" (big bang) (o famoso "ovo cósmico", no qual estaria condensada toda a massa/energia) coloca em andamento um processo de expansão, contrabalançando pela atração gravitacional, que funciona no sentido de desacelerá-la e, a partir de certo ponto, inverte o movimento expansivo; este se transforma em movimento de contração e vai aproximando a matéria das condições iniciais de todo o processo; no limite ter-se-ia uma reprodução quase exata do núcleo originário (PENA, 1989, p. 195.
\end{abstract}

São defensores dessa teoria sobre o fim da criação: Alexander Friedman que disse, em I92I, o universo tem estado a expandir-se desde o Big Bang; Edwin Hubble que, em 1929, baseando-se nas observações das estrelas variáveis em galáxias longínquas, chegou à conclusão de que o universo estava em expansão; Georges Lamaitre que, em 1933, apresentou uma teoria que se tinha chamado a teoria do Big Bang da origem do universo.

- Universo em expansão ilimitada. Segundo esta teoria, o universo tem princípio, mas não tem fim; aproxima-se tendencialmente do infinito.

\title{
Disserta Pena:
}

A partir do big bang inicial, dá-se um movimento de expansão indefinida; a quantidade de matéria é insuficiente para inverter essa tendência expansiva, como ocorria no modelo anterior. Correlativamente, registra-se uma diminuição progressiva da densidade da matéria, que chegaria, no limite, ao valor zero (PENA, 1989, p. 195).

- Universo pulsante (ou universo fênix): De acordo com esta teoria, não existe nem um princípio único nem um término único, mas uma sucessão ilimitada de pulsações num universo eterno. Pena afirma: "Trata-se de uma variação do primeiro modelo. Uma vez alcançado o estado originário, uma nova explosão causa a repetição de todo o ciclo expansão-contração, e assim indefinidamente" (PENA, 1989, pp. 195-196).

- Universo estacionário: segundo esta teoria, não é necessário perguntar pelo princípio ou o término do universo. Quer dizer, o universo não teve começo nem terá fim e que sua densidade permanecerá constante.

À respeito, escreve Pena:

O universo permanece substancialmente estável para qualquer observador, seja qual for sua posição espacial ou temporal. Sua densidade média mantém-se eternamente constante: os efeitos do fato inegável da expansão são 
contrabalançados por uma permanente injeção de matéria adicional (uma espécie de creatio ex nihilo continua) (PENA, 1989, p. 196).

É defensor dessa teoria, Fred Hyle que em 1948, propôs a teoria de um universo estático, chamada Teoria do Estado Estacionário.

\subsection{Avaliação crítica das quatro teorias}

A teoria estacionária não se sustenta cientificamente e portanto está virtualmente pela cosmologia e a astrofísica contemporânea. À respeito, Crea afirma: "foram necessários menos de vinte anos para que a maioria dos cosmólogos se convencesse de que as observações experimentais quase refutaram o modelo do estado estacionário" (CREA, citado por ENA, 1989, p. 196).

De fato, as teses da teoria estacionária são mais metafísicas que empíricas; não se explicam como nem onde é criada a matéria adicional.

Diz Pena:

o modelo choca-se, por outro lado com o dado experimental do enigmático sinalrádio (ou "radiação cósmica de fundo") que constantemente recebem todos os observatórios e que, descoberto fortuitamente por dois astrônomos americanos em 1965, é comumente interpretado como autêntico resíduo fóssil do big bang (PENA, 1989, p. 196).

No que diz respeito à teoria três, isto é, ao universo pulsante, pode-se afirmar que ela é uma variação filosófica da teoria do Universo em expansão, idealizada para iludir o problema metafísico: o que havia antes do big bang, de onde procede o ovo cósmico, o que foi que provocou a explosão, etc. Como se pode ver, portanto, sua validez não depende de razões científicas: trata-se de opção empiricamente não-convalidável.

Portanto, a discussão parece ficar finalmente circunscrito às teorias do Universo em expansão limitada e do Universo em expansão ilimitada

Por isso, a partir de 1998, através das observações das supernovas em galáxias, surgem teorias recentes cosmológicas sobre o destino final do universo. Segundo essas teorias, as galáxias estão ganhando velocidade, ou seja, estão acelerando, estão em expansão. 


\subsection{As recentes teorias sobre o futuro do universo}

A presente expansão há de continuar indefinidamente ou há de diminuir e o universo por fim vai entrar em colapso? As recentes e rivais teorias científicas predizem se o universo terá duração finita ou infinita. Portanto, existem duas possibilidades sobre o fim do universo:

$$
\begin{aligned}
& \text { A primeira possibilidade: o universo continua em expansão } \\
& \text { eternamente, resfriando-se cada vez mais. As fontes de energias } \\
& \text { como as estrelas acabariam por extinguir e o universo teria um fim } \\
& \text { gelado (Big Rip); } \\
& \text { - A segunda possibilidade: a expansão cessa no futuro e o universo } \\
& \text { começa a contrair-se, com as galáxias } \quad \text { voltando a se aproximar } \\
& \text { uma das outras e conseqüentemente esquentando novamente o } \\
& \text { universo. Nesse caso, o universo teria um fim quente (Big Crunch). } \\
& \text { Diante dessas duas possibilidades, é inevitável perguntar: qual das duas }
\end{aligned}
$$
possibilidades de fato ocorrerá?

Segundo as teorias cosmológicas atuais, a quantidade de matéria que há no universo é a que decidirá o futuro do mesmo. O índice de expansão do universo depende da quantidade de matéria que ele contem.

Pode-se calcular que se a densidade do universo é menor que três átomos por metro cúbico, será suficiente para frear a expansão, o universo se expandirá indefinidamente (Big Rip) e será condensado a uma morte fria no meio da escuridão mais absoluta. Nesse caso, o tempo acabar-se-ia em uns 35.00o milhões de anos.

Mas se a massa é suficiente para deter a expansão, terá lugar o Big Crunch ou, o universo, forçado pela grande quantidade de massa, começaria a comprimir-se até que, dentro de 20.000 milhões de anos, acabe por colapsar-se em quente. Nesse caso depois do fim quente é possível que o universo comece de novo com outro Big Bang.

Hsu não vê os perigos para o nosso planeta em quaisquer causas naturais intrínsecas, visto que a criação possui seus mecanismos de auto-ajustamento ao longo de milênios.

Quanto ao nosso planeta, está vivo, povoado por organismos vivos pelo menos há 3,5 bilhões de anos. Desde então, a Terra sempre foi viva. Com oceanos que nunca 
ferveram nem congelaram totalmente até o fundo, a vida na Terra jamais foi completamente exterminada (HSU, 1998, p. 71).

Segundo Kennet, a quantidade de energia solar foi menor no começo, mas a radiação solar aumentou há cerca de 3 bilhões de anos, e permanecerá mais ou menos constante durante os últimos dois bilhões de anos. Não tem havido variações sistemáticas na história da Terra, nem mudanças climáticas. Os organismos vivos na Terra dispõem de um mecanismo de feedback: sistema auto-regulador.

Para o autor em questão, há dois tipos de organismos vivos na terra: os "aquecedores" e os "condicionadores de ar".

A história do clima da Terra tem sido desde então um contínuo registro de um domínio alternado dos "condicionadores de ar" e dos "aquecedores". Por exemplo, quando o nosso planeta ficou superaquecido, faz uns dois bilhões de anos, Gaia ${ }^{2}$ os deu um "condicionador de ar" e quando o "condicionador de ar" estava a ponto de tornar a terra um bloco de gelo, Gaia reagiu e nos deu os "aquecedores" e, assim, o clima na terra se tornou mais ameno.

$\mathrm{Na}$ opinião do nosso autor, se o nosso planeta morrer, não será por causas naturais. A mortalidade do planeta seria causada pela ambição da nossa espécie, mas, então nem Gaia poderia salvar-nos.

Essas contribuições científicas partilham, embora por diferentes razões, a modéstia dos teólogos, ou seja, da fé cristã, em procurar saber qual é o futuro da criação.

\section{LEITURA CANÔNICA DA BÍBLIA SOBRE O FUTURO DA CRIAÇÃO}

Teresa Okure, a partir da leitura canônica da Bíblia, descobre as conexões entre a criação e a escatologia que perpassam a história bíblia.

A perspectiva bíblica aceita a mensagem da Bíblia como revelação. Esta revelação começa com a criação de "céu e terra" (Gn I,I-2,4) e termina com a criação de "um novo céu e uma nova terra" (Ap 21-22). Proclama a presença e a ação de Deus na história para assegurar o cumprimento do plano divino contra o assalto do mal.

Portanto, a tese da fé apocalíptica é a seguinte: Deus criou o mundo muito bom. Através do dolo da serpente, o mal entrou no mundo, trazendo pecado e morte para os

\footnotetext{
${ }^{2}$ Gaia, na mitologia grega, é a Mãe-Terra, como elemento primordial e latente de uma potencialidade geradora imensa.
} 
seres humanos e ruína para a criação. Em Apocalipse 12,19, esse inimigo da humanidade e da criação é chamado de "dragão, a serpente primitiva... o demônio ou Satã. A resposta imediata de Deus foi prometer à humanidade a vitória sobre a serpente/Satã (Gn 3,15).

Vista dentro de todo quadro bíblico, a crença na vitória de Deus sobre Satã é alma da fé bíblica. Jeremias fala dela em termos de "nova aliança” (Jr 31,31-34). Isaías enunciou "novo céu e nova terra" (Is 65,17). Para Paulo, não apenas os seres humanos, mas toda a criação beneficiar-se-á com a vitória final de Deus em Cristo, sendo libertada da sujeição à corrupção:

Eu penso que os sofrimentos do tempo presente não têm proporção com a glória que há de ser revelada em nós. De fato, toda a criação espera ansiosamente a revelação dos filhos de Deus; pois a criação foi sujeita ao que é vão e ilusório, não por seu querer, mas por dependência daquele que a sujeitou. Também a própria criação espera ser libertada da escravidão da corrupção, em vista da liberdade que é a glória dos filhos de Deus ( $R$ m 8, 19-2I).

A história bíblica traz embutida uma perspectiva de futuro, seja em termos da expectativa messiânica da parusia ou em termos da fé apocalíptica do Apocalipse.

De acordo com as tradições bíblicas, a história universal começa com a benção primitiva da criação temporal e terminará com a bem-aventurança da eterna criação: "Eis que faço novas todas as coisas" (Ap 21,5). Isto é o "novo céu e a nova terra", com que o "primeiro céu a primeira terra "hão de desaparecer (Ap 2I,I).

Para Teresa Okure, Ap 21-22 retoma a primeira criação $\left(G_{n}\right.$ I,I-2,4): já que a primeira criação foi simbolicamente amaldiçoada em conseqüência do pecado de Adão ( $\mathrm{G} n$ 3,17), a derrota final de Satã implica a redenção da própria criação; é este o motivo da criação do novo céu e da nova terra.

O novo céu e a nova terra não precisam de sol ou da lua, pois o próprio Deus é a luz (Ap 21,23). A terra/solo, originalmente criada boa (Gn I,II-I2; 2,9), mas amaldiçoada por causa do pecado, é agora tão fértil que suas árvores frutificam durante doze meses do ano... A árvore do conhecimento do bem e do mal, cujo fruto proibido trouxe a morte, desaparece; somente as árvores da vida com folhas que curam as nações, permanecem (Ap 22,2). Os temas da luz, da água do rio, que acompanham a primeira criação, afloram novamente nesta nova criação (cf. $\mathrm{G} n$ I,3-4.9-Io. 2,10-I4; Ap 21,5; 22,I-2) (OKURE, 1998, p. 34-35).

A fé apocalíptica crê, portanto, na soberania absoluta de Deus sobre a criação e imagina-o destruindo perversos, injustos e opressores sistemas de qualquer espécie. A fé apocalíptica está ligada à parusia (cf. Mc 13,26); seu cumprimento ela o espera do mesmo Deus que fez e cumpriu as promessas anteriores. 
Em resumo, pode-se dizer que a doutrina bíblica da criação e da queda torna necessária a fé apocalíptica. A preocupação primeira da fé apocalíptica é a erradicação definitiva do mal e a restauração do bem na criação, de acordo com o plano original de Deus. Esta fé apocalíptica é essencialmente uma fé bíblica, encontra seu fundamento sólido na ressurreição de Cristo.

\section{A LEITURA CRISTÃ SOBRE O FUTURO DA CRIAÇÃO}

A expectativa cristã de um futuro nada tem a ver com soluções finais do tipo "fim" da vida, o fim da história ou fim do mundo, mas antes o início da vida eterna, o início do Reino de Deus e o início "do mundo futuro". É o novo início de Deus no final desta vida no tempo, da figura deste mundo e desta criação temporal. A esperança cristã espera no fim o começo.

As expectativas do fim começam a ser cristãs quando abrem seus horizontes do futuro a partir da memória da crucificação e ressurreição do Cristo crucificado para a glória de Deus que há de vir. A esperança cristã do fim não é o prolongamento das linhas que evoluem das situações passadas e presente da história do mundo.

Para a esperança cristã, Cristo é a promessa, abertura e o verdadeiro início da

verdadeira vida em meio a esta vida, a nova criação de todas as coisas perecíveis para a eterna criação, e ainabitação de Deus em meio às paragens distantes de nossos desertos. Diz Moltmann: Não é o "fim do mundo" que traz o novo começo de Deus, mas antes o contrário: é o novo começo de Deus que leva este mundo errado ao seu merecido e ansiado fim. "Em si o aniquilamento de um mundo não possui nada de criativo" (MOLTMANN, 1998, p. 132)

O verdadeiro "fim do mundo" é apenas o início do "novo mundo de Deus" que está voltado para nós. Nada será destruído, tudo será transformado (cf. Prefácio católico do Dia de Finados). As dores do ocaso deste mundo de Deus são, portanto, algo assim como as dores de parto do novo mundo de Deus (cf. Rm 8,18ss).

A história do mundo possui uma meta e caminha passo a passo e com segurança rumo a esta meta. De acordo com as tradições bíblicas uma tal meta da história universal é o "reino milenar", onde Cristo com seus há de reinar em paz sobre os povos (cf. Ap 20).

Nova criação não se trata de outra criação que venha a substituir o mundo presente que já se conhece, mas sim de que esta criação que nós conhecemos passa a ser 

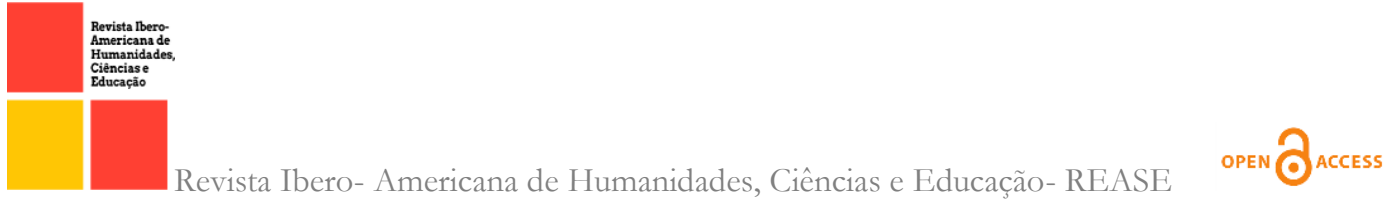

radicalmente diferente. Aquilo que já foi criado é "feito novo" (MOLTMANN, 1998, p. I40). Mas o que é que muda? Segundo Moltmann, é, em primeiro lugar, a relação com Deus: o criador, que criou sua obra, vem habitar e repousar em sua habitação. Sua "inabitação" (shekinah) entra no céu e na terra e faz ambos os mundos novos, ou seja, faz deles o templo cósmico de Deus. A glória de Deus habitará então em todas as coisas e iluminará e glorificará todas as criaturas.

Da idéia da inabitação cósmica de Deus segue-se, em segundo lugar, a idéia da transformação da criação temporal e mortal numa criação eterna e imortal. O que participa da glória de Deus passa a ser eterno e imortal como o próprio Deus. O que é destruído não é a criação em si, mas apenas sua forma de pecado, sua figura temporal e mortal. O que é glorificado ou, segundo a teologia ortodoxa, “divinizado” é o próprio ser criado.

O grande processo de transformação no final dos tempos é a passagem das contradições para a correspondência e do temporal para o eterno, e de mortal para a imortalidade da vida do mundo futuro. Deus não vem executar o mundo, mas sim para restaurar e corrigir. Nesse sentido, pode-se dizer: no fim - está Deus.

Portanto, como afirma Moltmann (1993, p.366):

uma leitura cristológia da criação nos mostra Cristo como o primogênito de toda a criação. Todas as coisas foram criadas com vistas ao Messias, porque o Messias redimirá todas as coisas para sua verdade e as reunirá para o reino de Deus e, dessa forma, levará a criação à consumação. Isso significa que Cristo está presente na natureza sacrificada. A vinda, então, de Cristo na glória acontecerá numa transformação de toda a natureza de modo que seja eternamente reconhecível como criação de Deus. Todas as coisas foram criadas pelo Messias e adquirem nele sua consistência.

\section{REFLEXÃO SOBRE FÉ/TEOLOGIA E CIÊNCIA EM DIÁLOGO}

A reflexão sobre a relação fé/teologia-ciência nos mostra que só no século $\mathrm{XX}$, a partir das posições de Pierre Teihard Chardin, alguns teólogos começaram a mostrar prudente abertura em relação ao tema "natureza", especificamente ao futuro da natureza. Isso foi mais fácil na teologia católica, que tradicionalmente acentua o tema da criação. Mas também do lado protestante a "natureza" foi descoberta como tema teológico. Não custa lembrar aqui, os grandes teólogos que refletiram sobre o tema da "natureza e/ou criação": M. de Jong, WolfhartPannemburg e J. Moltmann.

As iniciativas para refletir de maneira intensiva a relação fé/teologia - ciências naturais podem ser situadas, grosso modo, a partir dos anos 6o do século XX. 
A crise ecológica obriga toda a teologia séria a questionar o possível antropocentrismo emboscado na sua auto-compreensão. Todas as teologias da criação devem agora manter um diálogo com aquelas formas de ciência ecológicas, cujas próprias preocupações práticas são evidentes. Todas devem agora compartilhar da mesma atitude crítica e suspeita em face do tradicional enfoque científico teológico do direito humano a "dominar e explorar a natureza".

A generalizada preocupação, tanto entre cientistas como entre teólogos, com essa crise ecológica força a procura de uma nova interpretação cosmológica. As questões ecológicas e cosmológicas são urgentes, que somente um esforço cooperativo unindo os cientistas e teólogos, pode alimentar a esperança de se encontrar um meio para superar a crise. Hoje é impossível que a teologia compreenda como resposta aos desafios ecológicos sem levar em conta as questões cosmológicas. As questões cosmológicas devem reingressar em toda a teologia contemporânea. O que se impõe agora é um esforço cooperativo que ajude a estabelecer "correlações mutuamente críticas", e plausíveis, não só para interpretar o futuro da criação, mas também para ajudar a mudá-la diante da crise ecológica.

O diálogo entre a teologia da criação e as ciências cosmológicas, hoje, poderia começar com uma reflexão conjunta sobre uma categoria central da teologia cristã: a categoria da esperança. O redescobrimento das tradições proféticas, escatológicas e apocalípticas poderia ocasionar uma recuperação da esperança cósmica presente nas dimensões sapienciais dessas mesmas tradições.

[..... a categoria teológica da esperança desafia não só as ideologias históricas do progresso ocidental, evolucionista e liberal, mas também todas as cosmologias do pregresso (naturalistas-materialistas ou religiosas). As tradições sapiencial e profética reconhecem uma coisa que as ideologias do progresso não conseguem enxergar: a dura realidade do mal radical, a tragédia e o pecado em toda existência, e a necessidade de ações concretas e realistas contra esses males ações que se alicercem numa confiança-esperança fundamental: a esperança no Deus que comanda a natureza e a história simultaneamente (TRACY; LASH, 1993, p.128).

Não é possível, hoje, elaborar um único modelo cosmológico “científico" e exclusivo. Também não parece possível, no campo teológico, construir um cabal sistema de exaustiva e definitiva compreensão da criação.

Porém, já se vê uma realidade informada pela esperança que nos traz a concepção cristã de toda a realidade vista sob a perspectiva da crucifixão e ressurreição de Jesus Cristo. 
A cruz lembra claramente o ainda-não, o sofrimento e a tragédia no âmago de toda a existência. A ressurreição desvela a realidade da esperança cristã diante da natureza afirmando que Deus atua através do ministério e da cruz de Jesus Cristo. Portanto, Cristo continua a oferecer o prisma decisivo para a interpretação cristã da criação. $O$ trabalho teológico deve entrosar-se com todas as disciplinas (ciências naturais e cosmologia), competentes na interpretação da criação, sobretudo do futuro da criação.

\section{CONSIDERAÇÕES FINAIS}

Nesta parte conclusiva do artigo, pretendemos fazer uma síntese do caminho percorrido até aqui:

a) vivemos numa atual situação de crise ecológica. Segundo opinião praticamente unânime, os grandes problemas ecológicos se resumem em: contaminação ambiental, a exploração dos recursos naturais, o efeito estufa, o buraco do ozono. Como conseqüência desses problemas, assiste-se, em nível mundial, as transformações climáticas (grandes secas e enchentes), problemas agrícolas;

b) a leitura científica nos fala de duas possibilidades sobre o fim do universo: o universo continua em expansão eternamente, resfriando-se cada vez mais. As fontes de energias como as estrelas acabariam por extinguir e o universo teria um fim gelado (Big Rip); - a expansão cessa no futuro e o universo começa a contrair-se, com as galáxias voltando a se aproximar uma das outras e conseqüentemente esquentando novamente o universo. Nesse caso, o universo teria um fim quente (Big Crunch);

c) a leitura cristã nos mostrou que todas as coisas foram criadas com vistas ao Messias, pois o Messias redimirá todas as coisas para sua verdade e as reunirá para o reino de Deus e, dessa forma, levará a criação à consumação;

Universo infinito ou universo finito? As exposições precedentes mostram que estas perguntas são tão importantes para cosmólogos quanto para teólogos. Por isso, não podem ser respondidas apenas com base nos conhecimentos dispensados pelas ciências da natureza, pois nenhuma das teses em que se articula a doutrina cristã da criação entra em conflito com convicções comumente admitidas hoje pelos cultores das ciências.

\section{REFERÊNCIAS BIBLIOGRÁFICAS}

BRADLEY, I. Dios es 'verde': cristianismo y médio ambiente. Santander, Sal Térrea, 1993.

CAPRA, Fritjop. A Teia da Vida: uma nova compreensão científica dos sistemas vivos. São Paulo: Cultrix, 1996, p. 23-45; 231-235.

GRAY, E. D. Green paradise lost. Wellesley, Massachusetts Roundtable Press, I98I. 
HERVIEU-LÉGER, D. Religion et écologie. Paris, Les Editions du Cerf, 1993.

HSU, Kenneth J. A mortalidade do planeta. Concilium, Petrópolis:Vozes, n. 277, Abr./1998, pp. $7 \mathrm{I}^{-}-82$.

ISHAM, Christopher; ALBERECHT, Andreas. O futuro do universo. Concilium, Petrópolis:Vozes, n. 277, Abr./1998, pp. 84-94.

LEONE, S. Ecologia. In Cunha, J.T. (Coor.). Dicionário de Bioética. Aparecida: Santuário, $2001, \mathrm{p} \cdot 355^{-3}-355$

MOLTMANN, Jürgen. No fim - está Deus. Concilium, Petrópolis: Vozes, n. 277, Abr./1998, pp. 130-I40.

. Deus da criação: doutrina ecológica da criação. Petrópolis: Vozes, 1993.

RUIZ DE LA PENÃ, J.L. Realidade velada: cuando la física deviene metafísica. Razón y fe. agost. pp. 27-39, 1983.

OKURE, Teresa. Do Gênesis ao Apocalipse: a apocalíptica na fé bíblica. ConcíliumPetrópolis: Vozes, n. 277, Abr./1998, pp. 29-37.

TRACY, David; LASH, Nicholas. Reflexões teológicas conclusivas. Concílium. Petrópolis: Vozes, n. I86, Jun./1983, pp. 122-130.

WHITE, L. 1967. The historical roots of our ecological crisis. Science, Washington-DC, I55 (3767), pp.1203-1207, 1967. 